\title{
Microalbuminuria: associations with height and sex in non-diabetic subjects
}

\author{
M M Gould, V Mohamed-Ali, S A Goubet, J S Yudkin, A P Haines
}

Abstract

Objectives-To study the association(s) between microalbuminuria and cardiovascular risk factors in non-diabetic subjects.

Design-Patients aged 40-75 years were randomly selected from a general practice list and invited to participate.

Setting-Health centre in inner city London.

Subjects-Of those invited, 1046 out of 1671 $(62 \cdot 6 \%)$ attended. Subjects were excluded for the following reasons: not being white (44); urinary albumin excretion rate $>200 \mu \mathrm{g} / \mathrm{min}$ (3); having a urinary infection (5); taking penicillamine or angiotensin converting enzyme inhibitors (7); older than 75 (2); having diabetes (25); missing data on glucose concentration (1).

Main outcome measures-Glucose tolerance test results, albumin excretion rate from overnight and timed morning collections of urine; blood pressure; height.

Results-Mean albumin excretion rate was significantly lower in women than men (mean ratio $0.8,95 \%$ confidence interval $(0.69$ to 0.91$))$. Mean albumin excretion rate was significantly associated with age, blood pressure, and blood glucose concentration (fasting, 1 hour, and 2 hour) in men and inversely with height. Men who had microalbuminuria in both samples were significantly shorter (by $5 \mathrm{~cm}(1.3$ to $9.3 \mathrm{~cm}))$ than those who had no microalbuminuria in either sample when age was taken into account. In the case of women only systolic pressure was significantly associated with albumin excretion rate.

Conclusions-Microalbuminuria and short stature in men are associated. Cardiovascular risk has been associated with both of these factors and with lower birth weight. The inverse association of microalbuminuria with height is compatible with the suggestion that factors operating in utero or early childhood are implicated in cardiovascular disease. The higher prevalence of microalbuminuria in men compared with women may indicate that sex differences in cardiovascular risk are reflected in differences in albumin excretion rate.

Health Care and Medicine,

University College and

Middlesex School of

Medicine, Whittington

Hospital, London N19 5NF

M M Gould, research project coordinator

V Mohamed-Ali, research biochemist, department of medicine

S A Goubet, statistician

JS Yudkin, professor of medicine

A P Haines, professor of primary health care

Correspondence to: Ms M M Gould, Department of Primary Health Care.

BMF 1993;306:240-2 with microalbuminuria was 24 times higher. ${ }^{4}$ Height is inversely associated with risk of coronary heart disease,${ }^{78}$ and this observation has been considered evidence of factors acting in utero or in early childhood. ${ }^{9}$ We examined the relation between albumin excretion rate, height, and other cardiovascular risk factors in non-diabetic white subjects aged $40-75$ in north London.

\section{Subjects and methods}

Ethical approval for the study was obtained from the district ethics committee. The participants were recruited from a general practice in north London with a list size of around 8500 at the time of the study. A list of all patients aged 40-75 was obtained and those known to have diabetes were removed from it. Subjects were invited randomly by post to participate in the study. Patients with terminal illnesses were excluded from the study. Those who were eligible were advised that the screening procedure would take just over two hours and include blood tests, urine tests, measurement of height, weight, and blood pressure, and some questions about general health and current treatments. Those who did not respond to the first invitation were invited again in another letter. Anyone who defaulted was offered another appointment. The screening programme took place from May 1990 to September 1991.

\section{SCREENING PROCEDURE}

Participants were given a morning appointment and asked to fast from 2200 the preceding night. Compliance with this request was confirmed on arrival. After initial registration details had been completed blood pressure was taken with a random zero sphygmomanometer, and an oversize cuff (Hawksley Gelman, Lancing, Sussex) was used when appropriate; the fifth Korotkoff sound was taken as the measure of diastolic pressure. Venous blood was taken for fasting plasma glucose concentrations. A glucose load (75 g) (Fortical, Cow and Gate, Trowbridge, Wiltshire) was then given and further blood samples were taken after one and two hours for measurement of plasma glucose concentration.

Each subject filled in a questionnaire, which included items on serious illnesses and current treatments. The questionnaires were completed by the subject and checked by a researcher. If, however, the subject was unable to do this-for example, because of illiteracy or physical or mental impairment-the questionnaire was filled in by the subject's companion or the questions were asked orally by a researcher. Blood pressure was then measured for the second time on the same arm.

Height was measured without shoes and subjects were weighed wearing only light clothing on a balance with attached height measure (Seca). Body mass index was calculated as weight divided by the height squared $\left(\mathrm{kg} / \mathrm{m}^{2}\right)$.

A timed urine sample was obtained at the time of screening from all subjects and was tested with dipsticks for protein and blood and additionally for leucocytes and nitrites in the second half of the recruitment phase. When there was evidence of possible urinary tract infection, urine was sent for culture. A second, overnight, sample was requested from all subjects. 
ASSAY METHODS

Plasma glucose concentration was measured by a glucose oxidase technique (Beckman, Brea, California). Urinary albumin excretion was measured by an inhouse modified competitive enzymoimmunoassay, ${ }^{10}$ which was validated against a commercial radioimmunoassay $(r=0.96$; Pharmacia-LKB, Milton Keynes). Albumin excretion rate was calculated from this, and the mean of the two results (timed and overnight samples) after logarithmic transformation was used in the analyses except when indicated.

\section{CLASSIFICATION CRITERIA FOR ANALYSES}

Diabetes-Glucose intolerance and diabetes were defined by the criteria of the World Health Organisation. " Diabetes mellitus is classified as a venous plasma glucose concentration during a $75 \mathrm{~g}$ oral glucose tolerance test of greater than or equal to $7.8 \mathrm{mmol} / \mathrm{h}$ (fasting) or $11.1 \mathrm{mmol} / \mathrm{l}$ (two hours after the load).

Blood pressure-The means of the two systolic and diastolic blood pressures were used in the analyses.

Microalbuminuria-Subjects were classified as having microalbuminuria if they had an albumin excretion rate of $20-200 \mu \mathrm{g} / \mathrm{min}$ detected in either or both of the urine samples.

\section{DATA ENTRY AND STATISTICAL ANALYSIS}

The data were entered into a computer database using the Smartware II software package and analysed using the statistical package for the social sciences (SPSS). Albumin excretion rate was $\log _{\mathrm{e}}$ transformed because the distribution was skewed. Logistic regression was used for analysis of dichotomous variables and multiple linear regression for continuous data.

\section{SUBJECTS}

By the end of the screening programme 1671 eligible people had been sent letters asking to participate in the study; 1046 of them attended $(62 \cdot 6 \%)$. Of the nonattenders, $57(3.4 \%)$ defaulted, $67(4 \%)$ refused, and

TABLE I-Results of regression analysis of albumin excretion rate $\log _{e}$ transformed) adjusted for age in men

\begin{tabular}{|c|c|c|c|}
\hline Variable & $\begin{array}{l}\text { Regression coefficient } \\
\text { (95\% confidence } \\
\text { interval) per unit } \\
\log _{\mathrm{e}} \mathrm{AER}\end{array}$ & $\begin{array}{c}\% \text { Of } \\
\text { variation } \\
\left(R^{2}\right)\end{array}$ & $\begin{array}{c}p \text { Value } \\
\text { for } R^{2}\end{array}$ \\
\hline \multicolumn{4}{|c|}{ Blood glucose $(\mathrm{mmol} / \mathrm{l})$ : } \\
\hline Fasting & $0.25(0.04$ to 0.45$)$ & 3.5 & $\leqslant 0.0007$ \\
\hline $1 \mathrm{~h}$ & $0.07(0.03$ to 0.12$)$ & 4 & $\leqslant 0.0001$ \\
\hline $2 \mathrm{~h}$ & $0.12(0.04$ to 0.19$)$ & $4 \cdot 3$ & $\leqslant 0.0002$ \\
\hline \multicolumn{4}{|c|}{ Blood pressure $(\mathrm{mm} \mathrm{Hg})$ : } \\
\hline Systolic $(\mathrm{mm} \mathrm{Hg})$ & $0.01(0.01$ to 0.02$)$ & $6 \cdot 6$ & $\leqslant 0.0001$ \\
\hline Diastolic (mm Hg) & $0.02(0.01$ to 0.03$)$ & $7 \cdot 0$ & $\leqslant 0.0001$ \\
\hline Height $(\mathrm{cm})$ & $-0.02(-0.03$ to -0.01$)$ & 3.8 & $\leqslant 0.0004$ \\
\hline
\end{tabular}

TABLE II-Mean values (95\% confidence intervals) for height, glucose concentration, and blood pressure by category of microalbuminuria in men

\begin{tabular}{|c|c|c|c|c|}
\hline \multirow[b]{2}{*}{ Variable } & \multirow{2}{*}{$\begin{array}{l}\mathrm{p} \text { Value (analysis } \\
\text { of covariance) }\end{array}$} & \multicolumn{2}{|c|}{ Microalbuminuria in: } & \multirow[b]{2}{*}{ Neither sample } \\
\hline & & Both samples & One sample & \\
\hline Height & 0.026 & $168(164$ to 172$)$ & $172(170$ to 174$)$ & $173(172$ to 174$)$ \\
\hline \multicolumn{5}{|l|}{ Blood glucose $(\mathrm{mmol} / \mathrm{l})$ : } \\
\hline Fasting & 0.031 & $5 \cdot 0(4 \cdot 7$ to $5 \cdot 3)$ & $5 \cdot 1(4.9$ to 5.3$)$ & $4.9(4 \cdot 8$ to $5 \cdot 0)$ \\
\hline $1 \mathrm{~h}$ & 0.080 & $8 \cdot 7(7 \cdot 2$ to $10 \cdot 2)$ & $8.3(7.5$ to $9 \cdot 1)$ & $7.6(7.3$ to 7.9$)$ \\
\hline $2 \mathrm{~h}$ & 0.020 & $5 \cdot 1(4 \cdot 3$ to 5.9$)$ & $5 \cdot 6(5 \cdot 1$ to $6 \cdot 1)$ & $4.9(4 \cdot 7$ to $5 \cdot 1)$ \\
\hline \multicolumn{5}{|l|}{ Blood pressure $(\mathrm{mm} \mathrm{Hg})$ : } \\
\hline Systolic & 0.0001 & $139.3(129.0$ to 149.0 & ) $126 \cdot 2$ ( 121.0 to 132.0$)$ & $118.8(117.0$ to 121.0$)$ \\
\hline Diastolic & 0.0001 & $81 \cdot 4(74 \cdot 7$ to $88 \cdot 1)$ & $76 \cdot 7(72.8$ to $80 \cdot 6)$ & $70 \cdot 7(69 \cdot 4$ to $72 \cdot 0)$ \\
\hline
\end{tabular}

TABLE III-Multiple regression analysis of albumin excretion rate (log transformed) with height, blood glucose concentration, systolic blood pressure, and age in men

\begin{tabular}{lllllc}
\hline & \multicolumn{1}{c}{ Height } & 2 h Blood glucose & Systolic pressure & \multicolumn{1}{c}{ Age } & Constant \\
\hline Regression coefficient & -0.02 & 0.08 & 0.01 & 0.0006 & 2.20 \\
$95 \%$ Confidence interval & -0.03 to -0.0007 & 0.002 to 0.16 & 0.005 to 0.02 & -0.011 to 0.012 & 1.42 \\
\hline
\end{tabular}

Total $R^{2}=8 \cdot 4 \%, p \leqslant 0 \cdot 0001$.
TABLE IV-Regression analysis of factors associated with height in men (systolic pressure and blood glucose concentration two hours after glucose load) with adjustment for age

\begin{tabular}{lccc}
\hline Variable & $\begin{array}{c}\text { Regression coefficient } \\
(95 \% \text { confidence interval })\end{array}$ & $\mathrm{R}^{2}(\%)$ & $\begin{array}{c}\mathrm{p} \text { Value } \\
\text { for } \mathrm{R}^{2}\end{array}$ \\
\hline Systolic pressure $(\mathrm{mm} \mathrm{Hg})$ & $-0.231(-0.456$ to -0.007$)$ & $20 \cdot 1$ & $\leqslant 0.0001$ \\
2 h blood glucose $(\mathrm{mmol} / \mathrm{l})$ & $-0.029(-0.048$ to -0.010$)$ & $10 \cdot 1$ & $\leqslant 0.0001$
\end{tabular}

$501(30 \%)$ did not respond. Subjects were excluded from this analysis for the following reasons: $(a)$ they were not white $(44),(b)$ albumin excretion rate was greater than $200 \mu \mathrm{g} / \mathrm{min}$ (three), (c) they had evidence of urinary infection (five), (d) they were taking penicillamine or angiotensin converting enzyme inhibitors (seven), (e) they were older than 75 (two), $(f)$ they had diabetes (25), and $(g)$ data on glucose concentrations were missing (one). Thus a total study population of 959 remained, comprising 536 women and 423 men.

\section{Results}

The prevalence of microalbuminuria (albumin excretion rate $20-200 \mu \mathrm{g} / \mathrm{min})$ was $8.9 \%(81 / 913)$ in urine samples taken two hours after the glucose load and $5.8 \%(47 / 812)$ in the overnight samples, with $2.5 \%$ (19/774) showing microalbuminuria on both occasions. The prevalence of microalbuminuria differed significantly between men and women in the overnight sample $(8.9 \% v 3.3 \%, \mathrm{p}<0.001)$ but not in the two hour sample $(10 \cdot 7 \% v 7 \cdot 4 \%, \mathrm{p}<0 \cdot 1)$. Men had a significantly higher mean albumin excretion rate than women $(\mathrm{p} \leqslant 0.001$; mean ratio 0.80 (95\% confidence interval 0.69 to 0.91 ). The correlation of albumin excretion rate between the two urine samples was $0.46 \quad(n=774$, $p<0.001$ ). Because of the substantial differences in albumin excretion rate between the sexes, we analysed data for men and women separately.

Among the women mean albumin excretion rate ( $\log _{\mathrm{e}}$ transformed) decreased slightly with age $(r=$ $-0.08, p=0.08)$, but among the men it increased with age $(r=0.16, \mathrm{p}<0.003)$. All analyses were therefore adjusted for age.

MEN

Table I shows the associations of blood pressure, blood glucose concentration, and height with albumin excretion rate adjusted for age in the men (the percentage of variation, $R^{2}$, has been adjusted for the number of variables in the regression equation).

Analysis of covariance was used to test for mean differences in three categories of microalbuminuria: none on both occasions, microalbuminuria in one urine sample, and microalbuminuria in both samples (MM). The results are shown in table II. Mean height was significantly different in the group with microalbuminuria in both samples compared with the group with no microalbuminuria in both samples (difference between means $5 \mathrm{~cm}(1 \cdot 3$ to $9 \cdot 3))$.

Age, height, systolic blood pressure, and blood glucose concentration at 2 hours accounted for $8.4 \%$ of the variation in mean albumin excretion rate. The regression equation including all four variables is shown in table III. The strength of the relation between height and albumin excretion rate was reduced but remained significant when age, blood glucose concentration, and blood pressure were included in the equation.

Other associations of height are shown in table IV.

\section{WOMEN}

Table $\mathrm{V}$ shows the associations of blood pressure, blood glucose concentration, and height with albumin excretion rate adjusted for age in the women. Only the association with systolic blood pressure was significant. 
TABLE $\mathrm{V}-$ Results of regression analyses of albumin excretion rate $\left(\log _{e}\right.$ transformed) adjusted for age in women

\begin{tabular}{llll}
\hline Variable & $\begin{array}{c}\text { Regression coefficient } \\
(95 \% \text { confidence interval) }\end{array}$ & $\begin{array}{c}\% \text { Of } \\
\text { variation } \\
\mathrm{R}^{2}\end{array}$ & $\begin{array}{c}\mathrm{p} \text { Value } \\
\text { for } \mathrm{R}^{2}\end{array}$ \\
\hline Blood glucose (mmol/1): & & & \\
$\quad$ Fasting & $0.061(-0.096$ to 0.218$)$ & 0.4 & 0.17 \\
1 h & $0.010(-0.032$ to 0.051$)$ & 0.2 & 0.23 \\
2 h & $0.037(-0.024$ to 0.098$)$ & 0.5 & 0.12 \\
Blood pressure (mm Hg): & $0.008(0.003$ to 0.012$)$ & 2.7 & 0.001 \\
$\quad$ Systolic & $0.007(-0.001$ to 0.015$)$ & 0.8 & 0.06 \\
Diastolic & $0.006(-0.006$ to -0.018$)$ & 0.5 & 0.14 \\
Height & \multicolumn{3}{l}{} \\
\hline
\end{tabular}

\section{Discussion}

We found a prevalence of microalbuminuria of $8.9 \%$ in a single urine sample two hours after a glucose load. This is lower than the prevalence of $13.3 \%$ found by Haffner $e t$ al in Mexican-Americans ${ }^{5}$ and higher than the prevalence of $6.3 \%$ in the Winocour study in Newcastle, ${ }^{6}$ but it is similar to the $9 \cdot 4 \%$ found in the previous Islington study. ${ }^{4}$ Ethnic differences, age of subjects, selection bias, and different assay methods may have contributed to the differences. However, the Newcastle study defined microalbuminuria according to more rigorous criteria (albumin concentration greater than $20 \mu \mathrm{g} / \mathrm{ml}$ in conjunction with a ratio of albumin to creatinine concentration of greater than 3.5 ) and found a prevalence of $2 \cdot 2 \%$, which is similar to the prevalence of microalbuminuria of $2.5 \%$ detected in the two samples combined in our study.

We found that in men microalbuminuria was inversely associated with height and directly associated with blood glucose concentration (fasting and two hours after a glucose load) and systolic and diastolic blood pressures; in women microalbuminuria was directly associated with systolic pressure. Blood pressure and impaired glucose tolerance in adults are inversely related to birth weight and contribute to the increased cardiovascular risk associated with low birth weight. ${ }^{9}$ This study also shows that, in men but not women, blood glucose concentration and blood pressure are inversely associated with height, which is in turn influenced by birth weight and early childhood environment. ${ }^{12}$ An inverse association of height with risk of coronary heart disease has been found, ${ }^{78}$ and as microalbuminuria, blood glucose concentration, and blood pressure are negatively associated with height in men, these factors may have a role in the raised cardiovascular risk which accompanies short stature. The association of microalbuminuria with short stature suggests that the factors determining adult height may also influence renal structure or function in men

Absolute differences in cardiovascular risk between men and women are not explained by conventional risk factors. ${ }^{13}$ The higher albumin excretion rate in men might suggest that factors responsible for the increased cardiovascular risk in men also influence urinary albumin excretion. Males may be more affected by factors operating during the later stages of pregnancy as they gain more weight than females during the third trimester. ${ }^{14}$ If microalbuminuria, height, blood pressure, and glucose intolerance are in part determined by factors operating in the later stage of pregnancy, this could explain the coincidence of these abnormalities in adulthood, their association with cardiovascular risk, and the difference between the sexes in prevalence of coronary heart disease and various associated factors.

The study was supported by the Wellcome Trust. Diabetes and Related Diseases Research generously donated a microplate reader. We thank Paula Morgan, Siobhan Hamilton, Paul Dance, and Frances Southall for help with the screening. We also thank the patients and staff of the Goodinge Health Centre and Drs M T Cripwell, D Davidson, S T Hunt, M D Sills, and ME Tatham for their help and support.

1 Viberti GC, Hill RD, Jarrett RJ, Argyropoulos A, Mahmud U, Keen H. Microalbuminuria as a predictor of clinical nephropathy in insulindependent diabetes mellitus. Lancet 1982;i:1430-2.

2 Mogensen CE, Christensen CK. Predicting diabetic nephropathy in insulindependent patients. N Engl I Med 1984;311:89-93.

3 Mattock MB, Keen H, Viberti GC, El-Gohari MR, Murrells TJ, Scott GS, et al. Coronary heart disease and urinary albumin excretion rate in type 2 (non-insulin-dependent) diabetic patients. Diabetologia 1988;31:82-7.

4 Yudkin JS, Forrest RD, Jackson CA. Microalbuminuria as predictor of Yudkin JS, Forrest RD, Jackson CA. Microalbuminuria as predictor of
vascular disease in non-diabetic subjects: Islington diabetes survey. Lancet vascular disease in 1988 ;ii:530-3.

5 Haffner SM, Stern MP, Kozlowski Gruber MK, Hazuda HP, Mitchel BD, Patterson JK. Microalbuminuria-potential marker for increased cardiovascular risk factors in nondiabetic subjects. Arteriosclerosis 1990;10:727-31.

6 Winocour PH, Harland JOE, Millar JP, Laker MF, Alberti KGMM Microalbuminuria and associated cardiovascular risk factors in the community. Atherosclerosis 1992;93:71-81.

7 Marmot MG, Shipley MJ, Rose G. Inequalities in death-specific explanations of a general pattern? Lancet 1984; i: 1003-6.

8 Morris JN, Marr JW, Clayton DG. Diet and heart: a postscript. $B M \mathcal{F}$ 1977;ii:1307-19.

9 Barker DJP, Martyn CN. The maternal and fetal origins of cardiovascular disease. I Epidemiol Community Health 1992;46:8-11.

10 Chesham J, Anderton SW, Kingdon CFM. Rapid competitive enzymoimmunoassay for albumin in urine. Clin Chem 1986;32:669-71.

11 WHO Study Group. Diabetes mellitus. WHO Technical Report Series 1985; No 727 .

12 Kuh D, Wadsworth M. Parental height:. childhood environmental and subsequent adult height in a national birth cohort. Int $\mathcal{f}$ Epidemiol 1989;18:663-8.

13 Isles CG, Hole DJ, Hawthorne VM, Lever AF. Relation between coronary risk and coronary mortality in women of the Renfrew and Paisley survey: comparison with men. Lancet 1992;339:702-6.

14 Thomson AM, Billewicz WZ, Hitten FE. The assessment of fetal growth Journal of Obstetrics and Gynaecology of the British Commonwealth 1968;75: 903-16

(Accepted 13 November 1992)

\section{ONE HUNDRED YEARS AGO}

\section{"PEA-SOUP" FOGS.}

Dr. Poore lectured to a large audience at the Sanitary Institute on February 8th on a subject of much importance to all Londoners. After some interesting facts relating to the great fog of Christmas, 1891, which lasted 100 hours and was responsible for the death of about 1,400 persons, Dr. Poore stated that London fogs were really due not so much to smoky chimneys as was generally supposed, but to climatic conditions. The primary causes of fog were saturation, coldness, and stagnation of the air. Of these three, the last mentioned-the most serious from the point of view of health-was the only one which could be to any extent controlled by us. The average daily motion of the air, it was stated, was 300 miles. During the fog above mentioned the air at Greenwich was moving at the rate of 49 miles a day; but in the streets of our city the high buildings and the absence of straight and open thorough- fares so interfered with the current as to produce absolute stagnation. Thus for 100 hours London was breathing and rebreathing the same air with the direst results. Smoky fires certainly aggravated the evil; but, even if perfect combustion could be ensured, the deleterious nature of the fog would not be lessened as much as was popularly imagined. Analysis of fog deposit showed that 33 per cent. of it was of metallic origin, and was, therefore, quite independent of fires, while the sulphuric, carbonic, and other acids would result equally from perfect as from faulty combustion. The chief means of minimising the evil would be to keep people apart, to prevent overcrowding by the construction of high buildings, and to open up wide, straight thoroughfares in different directions so as to allow the air currents to move unchecked.

(BMF 1893;i:369.) 